\section{A new facility to enhance Australian GPS-geodetic research}

\author{
W E FEATHERSTONE, M P STEWART \\ School of Spatial Sciences, \\ Curtin University of Technology, \\ GPO Box U1987, Perth, WA 6845.
}

C RIZOS, $S$ HAN

School of Geomatic Engineering,

The University of New South Wales,

Sydney, NSW 2052.

\section{R COLEMAN}

Centre for Spatial Information Science,

School of Geography and Environmental Studies,

The University of Tasmania,

Hobart, Tas 7001.

\section{P TREGONING}

Research School of Earth Sciences,

The Australian National University,

Canberra, 0200 ACT.

\section{P J MORGAN}

School of Computing,

Faculty of Information Sciences and Engineering,

The University of Canberra,

PO Box 1, Belconnen, 2616 ACT.

\footnotetext{
Abstract

The Australian Research Council recently awarded a grant to a consortium of five Australian universities to purchase ten geodetic-quality GPS receivers and peripherals. This cooperative approach will enhance new and existing GPSgeodetic research opportunities for Australian academic geodesists. These research projects include the monitoring of deformation of man-made structures and natural features, global and regional plate tectonics, measurement of sea-level change, mapping of Antarctic ice sheets and their flow, sounding of the Earth's atmosphere, and experiments in kinematic and rapid-static GPS-geodesy.
}

\section{INTRODUCTION}

In 1999, the Australian Research Council (ARC) awarded a $\$ 200,000$ grant to a consortium of five Australian universities through its Research Infrastructure and Equipment Facilities Program (RIEFP). This was supplemented by a further $\$ 200,000$ from these universities. These funds have allowed the purchase of 10 dual-frequency GPS receivers, 16 DorneMargolin-type choke-ring antennae with hemispherical radomes, four notebook computers, and associated software and cables. This GPS Receiver Pool will support and enhance a wide variety of internationally relevant research projects by geodetic scientists at these universities.

The GPS Receiver Pool will be used to collect the data that are essential for existing and new GPS-geodetic research projects. Most of these projects involve close collaboration and cooperation among the members of the consortium (who are listed as authors of this paper), as well as with investigators from universities and government agencies both within Australia and overseas. The GPS-geodetic research projects described in this paper include deformation monitoring on local and regional scales, vertical monitoring of tide-gauge sites, Antarctic geodesy and glaciology studies, kinematic and rapid-static GPS-geodesy, atmospheric sounding, and a range of complementary GPS-geodetic projects.

It is important to acknowledge that GPS-geodetic research is undertaken at other Australian universities and government agencies (notably the Australian Surveying and Land Information Group - Manning et al., 1998), but this paper will only summarise the current and future research activities of the consortium using the GPS Receiver Pool. Therefore, the list of references mostly includes papers by the researchers at the consortium universities, and it should not be interpreted that similar research is not undertaken by these other organisations, which is reviewed in Coleman (1999; http://www.science.org.au/internat/natcomm/geodesy.pdf).

\section{The Consortium}

Due to the ever-decreasing amount of government research funding to Australian universities, it has become necessary for academic researchers to form consortia and share equipment wherever possible. This arrangement is quite sensible in the case of portable equipment such as GPS receivers, which can easily be transported between institutions for specific research projects. Moreover, it avoids the Australian taxpayer having to fund similar research programs at several institutions that would normally be expected to collaborate. This also gives the researchers an opportunity to explore a wider range of projects that may not be achieved by individually funded grants.

The seven individuals comprising this consortium are employed at those academic departments in Australia that have a well-established track record of GPS-geodetic research. The universities involved comprise The University of New South Wales (UNSW), Curtin University of Technology (CurtinU), The University of Tasmania (UTas), The University of Canberra (UCanb) and the Australian National University (ANU). Importantly, this consortium further strengthens the breadth and scope of research able to be undertaken by Australian academic geodesists. 
It must be emphasised that the consortium already has an excellent working relationship, as evidenced by joint publications (eg. Ananga et al., 1995; King et al., 2000; Morgan et al., 1996; Phillips et al., 1998; Tregoning et al., 1998a; White et al., 1994), a number of collaborative grants supported by the Australian Research Council (eg.

Featherstone and Rizos 1997 RIEFP grant; Morgan, Coleman and Rizos 1993 large grant; Coleman and Morgan 1998 large grant), as well as other informal collaborative projects.

\section{The Equipment}

After a competitive tender process, where the principal selection criteria were leading-edge GPS technology for highaccuracy applications, price, functionality and level of local user support, ten Leica CRS1000 dual-frequency GPS receivers were purchased in June 1999 (Figure 1). These receivers track code and full-wavelength carrier-phase data from the GPS satellite constellation on the L1 and L2 broadcast frequencies.

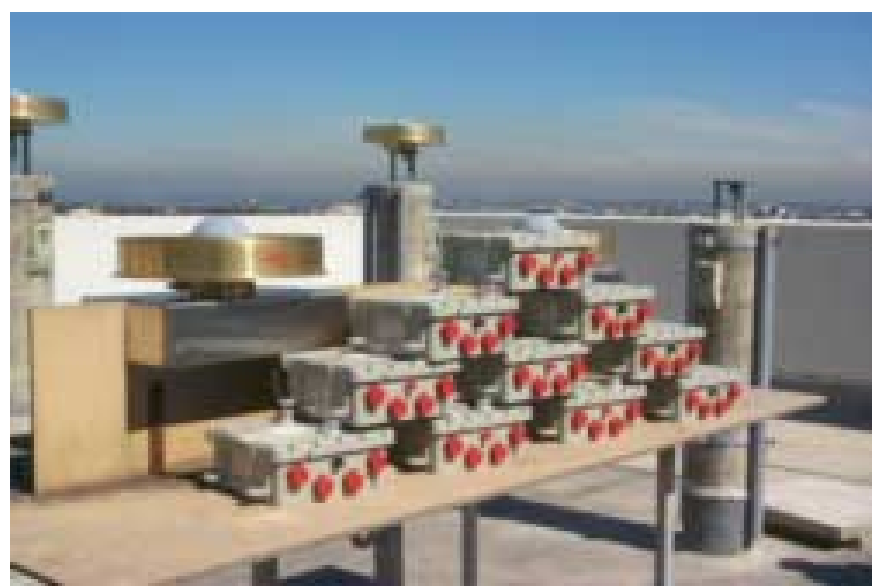

Figure 1. The Leica CRS1000 GPS receivers and choke-ring antennae assembled before testing at UNSW

Sixteen Dorne-Margolin-type antennae were also purchased (Figure 1). These choke-ring antennae are necessary to mitigate multipath, which is a site-dependent error that affects high-accuracy GPS positioning, especially in the challenging environments in which the equipment will be used (described later). An additional six choke-ring antennae were purchased so that these can be permanently placed at sites where smallmagnitude deformations are being monitored, such as at tidegauge sites and in seismically active regions. Standard hemispherical radomes accompany the choke-ring antennae to comply with international standards and to keep contaminants (eg. snow, litter, etc) out of the choke rings.

Five copies of the Leica proprietary GPS processing software, SKI Pro, were purchased for pre-processing of the data. However, this software will not be used routinely for processing the data collected during GPS-geodetic research projects. Instead, in-house and established geodetic software suites will be used, which have been developed at the collaborating universities as part of their existing research programmes. This research-based software allows more flexibility for project-specific applications. Moreover, it is sophisticated in that it models GPS error sources that are neglected by many commercial GPS data processing suites.
The Leica CRS1000 GPS receiver systems are fully portable and can be easily moved among the consortium members for periods of concentrated or strategic research. Custom-made aluminium cases have been constructed to safely transport the equipment to/from/in the field and among institutions. Some of the GPS equipment will be deployed over long periods (several months or years) in a quasi-permanent mode, whilst other projects will require short-term deployment for campaign-based fieldwork. Importantly, the additional six antennae will make the usage of the GPS Receiver Pool more flexible, because long-term installation of antennae at quasipermanent sites will not need to be disturbed during shortterm removal of the GPS receivers to support other projects.

\section{GEODETIC APPLICATIONS OF GPS}

Carrier-phase-based GPS positioning is now used extensively for many geodetic, surveying and precise navigation applications, and is also the subject of ongoing research at many different levels. Whilst excellent levels of accuracy are generally achievable using the available proprietary software, research into new techniques and applications of the GPS are consistently yielding improved results. Since the early 1980s, advances in GPS carrier-phase-tracking hardware, data analysis techniques and field procedures have made GPS positioning a fundamental tool in geodetic and geophysical research.

To achieve high-accuracy GPS-geodetic research results mandates the following:

- high-quality receivers and antennae able to make carrierphase and code pseudo-range measurements on both Lband frequencies (so-called 'dual-frequency geodetic' instruments);

- $\quad$ sophisticated data processing and analysis software, which can model all the physical parameters that adversely affect the GPS observations and thus bias the position results; and

- $\quad$ static, simultaneously tracking of GPS satellites over long observation sessions (from several days to years).

As a result of the increased sophistication of GPS measurement technology and data processing, relative precisions down to the level of $\pm(5 \mathrm{~mm}+1-10$ parts per billion) is being achieved almost routinely from geodetic GPS networks. This high level of precision is possible for receivers that are separated by distances from several hundreds to thousands of kilometres. Post-processing of the data using research-based software, which includes options for satellite orbit modelling, signal propagation delay modelling and digital signal processing, is required in order to achieve such high levels of precision. It also requires the use of precise GPS satellite orbit data, which are available from the International GPS Service (described later). Alternatively, most consortium members compute their own GPS ephemerides (Morgan et al., 1996; Tregoning et al., 1998).

These GPS data processing and analysis procedures were first established in the early 1980s, but have been significantly improved to the level that the GPS can now be used to measure the contemporary drift of continents and stability of 
natural features and man-made structures. The range of GPSgeodetic applications being addressed using traditional and new GPS-geodetic techniques continues to grow rapidly and includes:

- establishment of national geodetic datums, such as the Geocentric Datum of Australia (eg. Morgan et al., 1996; Stewart et al., 1997);

- maintenance of the global reference frame, including the determination of Earth orientation parameters and temporal variations in the position of the geocentre;

- quantification of the magnitude and direction of regional and global crustal motion, both in the horizontal and vertical directions (eg. Tregoning et al., 1998a, 1998b and 1999b; Featherstone, 1998);

- local deformation monitoring of ground monuments or human-made structures (eg. Roberts and Rizos, 1998; Stewart and Ffoulkes-Jones, 1995; Watson and Coleman, 1998);

- accurate determination of the coordinates of survey monuments, or the trajectory of antennae, in a welldefined reference frame, in support of a number of specialist applications (eg. Drane and Rizos, 1997; Featherstone, 1995; Han et al., 1999);

- atmospheric sounding, including water vapour measurement (eg. Tregoning et al., 1998c) and the monitoring of ionospheric activity (eg Lin and Rizos, 1996; Fu et al., 1999).

Current GPS-geodetic research activity in Australia and overseas challenges a range of further constraints to highprecision carrier-phase-based positioning. These include techniques that are applicable when the GPS antennae are in motion, the length of observation sessions are significantly shortened, or the positioning results need to be determined in real-time. The members of this consortium are investigating all of the above areas, and will continue to do so at an enhanced level with the availability of the GPS Receiver Pool.

\section{GPS-geodesy: The International Context}

By definition, geodesy has always been a global science. In the past 15 years, the GPS has revolutionised the geodetic and geophysical research methodology. This is because GPS instrumentation is highly portable, of comparatively low-cost (in relation to other space geodetic techniques such as verylong-baseline interferometry (VLBI) and satellite laser ranging (SLR)), and is capable of high-precision position determination over large distances.

The era when large, campaign-style GPS-geodetic surveys to support individual projects, requiring a large amount of organisation between many institutions, has ended. The availability of the global International GPS Service tracking network (Figure 2) and the level of GPS orbit precision from this service means that one no longer needs to organise massive campaigns. Instead, a network of sites can be observed individually, at any time and be combined to provide site coordinates at the $10 \mathrm{~mm}$ level (or better). This introduces more flexibility into the campaigns and thus allows a wider range of applications to be investigated using the GPS.
Therefore, the future approach to GPS-geodesy is likely to be characterised by:

- more GPS receivers being deployed on a permanent, continuously operating basis or on quasi-permanent basis with permanent antennae;

- a greater degree of cooperation between investigators and geodetic agencies (eg. to take advantage of the multifunctional capabilities of modern GPS receivers); and

- the development of new GPS-geodetic techniques in the form of innovative software and techniques.

An important justification for permanent and quasi-permanent GPS array networks is that geodetic research will be enhanced because of the continuous measurement of a deformation phenomenon, rather than a sporadic measurement. Such GPS instrument arrays may be established:

- across small areas, where they mostly monitor local deformations and deformation rates;

- across a country, as part of the fundamental backbone of the geodetic datum, and in support of general users from the surveying and navigation community; and

- $\quad$ increasingly as part of the global GPS receiver network coordinated by the International GPS Service (IGS).

The IGS permanent GPS network includes several hundred geodetic-quality GPS receivers (Figure 2), whose raw code and carrier-phase data are made available over the Internet. This allows for baselines to be processed with respect to these stations, thereby reducing the number of GPS receivers that are required for any campaign. The IGS also produces a number of other GPS-geodetic products, the most important of which are precise GPS ephemerides. Unlike the broadcast ephemerides, which are predicted from measurements made by five USA-controlled tracking stations, the precise ephemerides are post-processed in the ITRF reference frame from actual GPS observations made by the global IGS tracking network.

Permanent and quasi-permanent GPS array networks allow site velocities to be estimated very precisely (ie. to better than $2 \mathrm{~mm} / \mathrm{yr}$ ). Such a level of precision enables the GPS data to be used to investigate geophysical phenomena that were previously unable to be detected above the noise of the campaign-based GPS measurements (cf. Featherstone, 1998). Such applications include ground deformation, seismic strain accumulation and land uplift or subsidence. Also, continuously operating GPS sites support general users from the surveying and navigation communities, and contribute to the global GPS reference receiver network coordinated by the IGS. This is particularly important in the Southern Hemisphere, where there are significantly fewer IGS stations than in the Northern Hemisphere (Figure 2). 


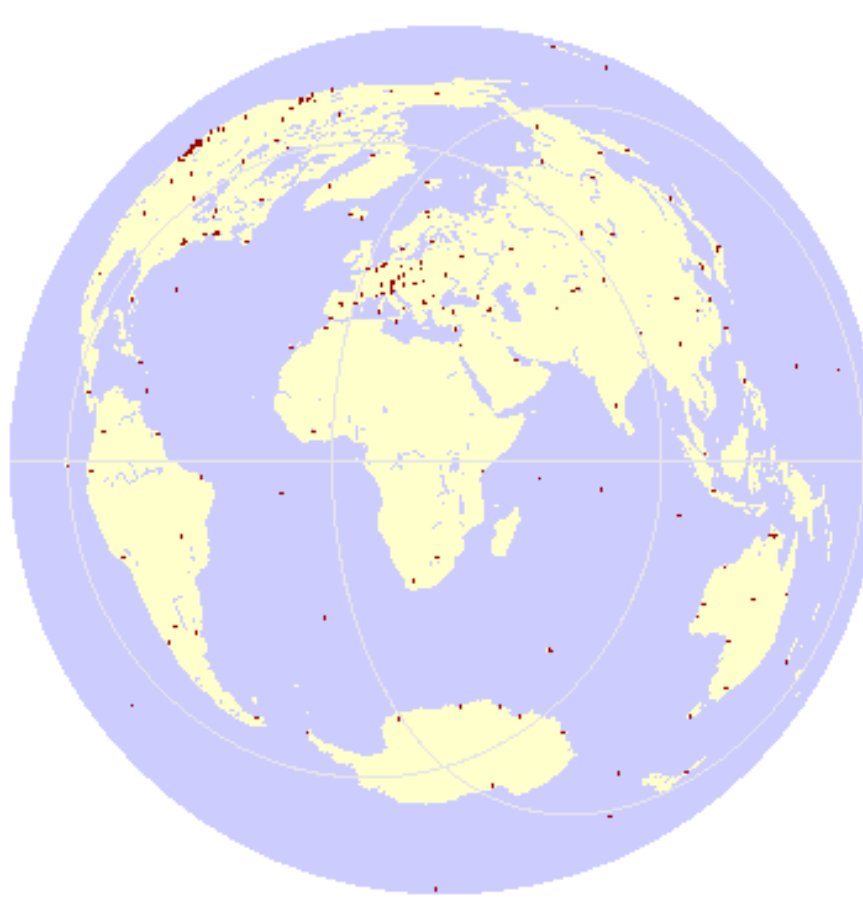

Figure 2. Global distribution of tracking stations comprising the International GPS Service network (image courtesy of the IGS Central Bureau's web-page)

Due to the IGS, the GPS Receiver Pool can support many more geodetic research projects, at no additional cost. Consortium and other investigators now only need to focus on deploying GPS receivers where they are required by the project or application and for as long as it is necessary to collect the field data. The length of time that the equipment will be used on projects may vary considerably; in some cases the receiver sites will be quasi-permanent, and in other cases they will be deployed for short field-campaigns. The IGS data, and the precise products derived from these data by a number of analysis centres around the world, are then processed and analysed with the investigator-collected GPS data. Importantly, the GPS Receiver Pool consists of dualfrequency receivers of the same quality as those installed at IGS stations so as to ensure Australia's geodetic research is internationally competitive and contributes to global geodesy.

\section{GPS-geodesy: The Australian Context}

Australia has a long history of GPS-geodetic research, beginning in the late 1970s. In addition to the staff expertise in Australian universities, companies and government organisations, this results from:

- Australia's unique geographic location (a significant landmass in the Southern Hemisphere), which serves as an important geodetic observing platform in global programs and makes a useful field laboratory;

- the need to develop and maintain high-accuracy geodetic datums for subsequent surveying, mapping and charting;

- Australia's scientific and mapping activities in its Antarctic territories;

- Australia's location on the edge of the South-east Asian and South Pacific 'ring of fire', which draws it into GPSgeodetic project partnerships with its immediate neighbours that seek to increase the understanding of volcanic and earthquake phenomena;
- Australia's location in the South Pacific, which is a lowelevation region of the world that is extremely concerned about sea-level rise due to 'global warming'; and

- a tradition of providing support to the less-developed countries of the region in implementing geodetic programs that also address their national needs.

The partners of this consortium have contributed to all of the above GPS-geodetic programs, and expect to continue at an enhanced level with the availability of this GPS Receiver Pool.

It is also important to acknowledge the contributions made to Australian, regional and global geodesy by the Australian Surveying and Land Information Group (AUSLIG). AUSLIG has installed and currently maintains the Australian regional GPS network (Figure 3), which is an important component of the IGS and provides reference frame definition in this part of the world. AUSLIG's continued role in GPS-geodesy will allow the consortium members to utilise these GPS data for studies in Australia. A useful review of AUSLIG's past and future contributions to Australian and global geodesy is given in Manning et al. (1998). GPS-geodetic research activities are also being investigated at other universities and organisations in Australia. However, as stated in the Introduction, this paper will only concentrate on the research activities of this consortium.

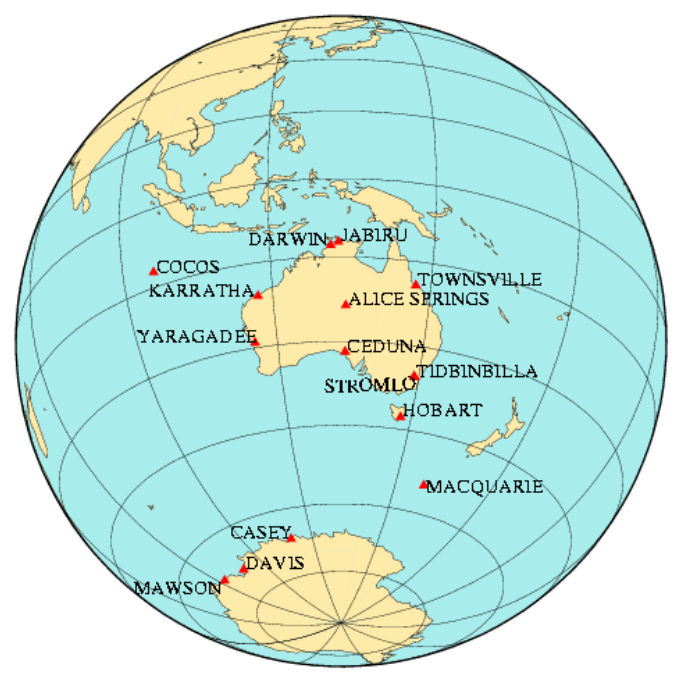

Figure 3. The Australian regional GPS network (image courtesy of AUSLIG's web-page)

\section{THE NEEDS FOR GPS-GEODETIC RESEARCH IN AUSTRALIA}

Prior to the award of this ARC grant, the level of GPSgeodetic research performed in Australia was limited by the lack of availability of high-quality GPS equipment, and thus was somewhat sporadic. One exception was the GPS Consortium (GPSCO) in New South Wales. However, there was previously no equipment facility available in Australia that specifically supported nation-wide university research in GPS-geodesy. Therefore, this GPS Receiver Pool now represents a unique Australian GPS-geodetic research asset. Essentially, the facility will serve a similar function to UNAVCO (University NAVSTAR Consortium) in the USA, 
which is supported by funding from the National Science Foundation (the USA's equivalent of the ARC) and the National Aeronautics and Space Administration (NASA).

All partners of the Australian GPS consortium have previously been forced to undertake their GPS-geodetic research projects using borrowed or hired GPS equipment, or have worked with datasets collected by other organisations. These arrangements have limited the ability of the researchers to define and execute their own research projects, particularly when international collaborators were involved. The GPS Receiver Pool avoids this undesirable scenario, and now supports a wide range of research projects - not just a single project - in GPS-geodesy. Moreover, it facilitates the launch of new initiatives by the consortium partners. In particular, the GPS Receiver Pool will provide the basis for research projects not previously practicable in Australia, such as those that demand long-term GPS receiver deployment.

\section{The Benefits to Australia}

According to the ARC's five priority funding criteria, the GPS-geodetic research programs will confer the following benefits to Australia.

- Contributions to the quality of our culture: The research programs (described later) will contribute fundamental knowledge in a number of important Earth science and engineering disciplines. For example, improved deformation monitoring will lead to increased safety in open-pit mines and those areas presently subject to geohazards, such as volcanoes and earthquakes. The region of South-east Asia and the South Pacific are particularly vulnerable to seismic hazard, hence geodetic studies of the present-day tectonic motions of the major plates, as well as numerous micro-plates, is an important activity. Studies of the variation in ice-sheet behaviour in Antarctica, as well as monitoring sea-level at tide-gauges using the GPS, are important for climate change studies.

- Graduates of high quality: The GPS Receiver Pool will increase the range of skills that graduates from the member universities will acquire prior to their entry to the Professions. The portability of the equipment will ensure that students at each institution will gain 'handson' experience in using the equipment for their projects. It is also estimated that, at any one time, up to fifteen research students will benefit from having access to the GPS Receiver Pool. Also, as there is an important nexus between research and teaching, the increased research expertise at Australian universities will be transferred to our graduates.

- $\quad$ Direct applications of research results: The GPS Receiver Pool will support a variety of scientific experiments, leading to new results and a greater understanding of present-day tectonics, isostatic rebound, ice-mass-balance changes, as well as implementation of steep-slope and volcano monitoring systems (described later). Such research is currently limited by the lack of readily available, high-quality GPS receivers to Australian researchers. Also, the consortium members have a long history of transferring the results of their research to Australian industry and government. The amount of this 'technology transfer' is expected to be enhanced with the GPS Receiver Pool.

- Increased institutional capacity for consulting, contract research or other service activities: The expertise at each institution will be enhanced in many existing and new areas of GPS-geodesy. Several of the projects to be supported by the GPS Receiver Pool involve novel features and data processing algorithms. Therefore, significant interest may be generated in the software, hardware and operational procedures that will be developed. There are likely to be opportunities to undertake further consulting/contract research across a number of application areas, the revenue from which will be used to enhance the equipment and purchase upgrades.

- International links: All of the consortium partners are members or chairpersons of international special study groups in their respective areas of expertise and have extensive research links with colleagues in North America, Europe and Asia. Many of these collaborative links will benefit further from the GPS Receiver Pool, because the Australian partner will be able to contribute GPS hardware and/or datasets to both regionally and internationally significant research projects.

\section{SCIENTIFIC RESEARCH ACTIVITIES USING GPS}

The GPS Receiver Pool will support a wide range of GPSgeodetic research projects of the consortium partners. These research projects both build upon the existing programs of the researchers and represent some new initiatives. The specific projects are categorised as follows.

\section{Regional plate tectonic monitoring}

The crust of the Earth consists of several tectonic plates that move in relation to one another, thus causing earthquakes when mechanical failure of the Earth's crust occurs. Previously, geological evidence was used to estimate the contemporary motions of these plates. However, space geodesy is the only technique that can reliably place constraints on present-day plate motion. Quantifying the magnitudes and directions of the deformation will help improve our understanding of the interaction of geological structure and crustal stresses that lead to seismic activity. These studies will provide knowledge crucial for assessing the seismic hazard to property and population in Australia and South-east Asia.

Members of the consortium have been and are currently very active in GPS-geodetic monitoring projects in Papua New Guinea, the Solomon Islands, Indonesia and south-west Western Australia.

- The consortium's previous GPS-geodetic projects in Papua New Guinea (Tregoning et al., 1998a, 1999b) have led to a geodetically derived model for the largescale relative motions of the Australian, Pacific, Woodlark and South Bismarck tectonic plates. They have also quantified that the boundary zone between the Pacific and South Bismarck plates is undergoing a present-day relative motion of $\sim 130 \mathrm{~mm} / \mathrm{yr}$, which is three times the magnitude of that along the San Andreas fault 
system. Future work in this region using the GPS Receiver Pool will place further constraints on the contemporary plate motion and refine the geodetically derived tectonic model.

- The consortium's previous GPS-geodetic projects in the Solomon Islands (Tregoning et al., 1998b) utilised GPS data and equipment from the University of South Australia. This revealed that the Solomon Islands are not rigidly attached to the Pacific Plate, but that there is a localised decoupling of the Solomon Islands Arc. These surveys will be repeated using the GPS Receiver Pool in order to improve the understanding of the mode of present-day motion in the collision zone between the Australian and Pacific Plates in this region.

- The consortium's previous GPS-geodetic projects in the intra-plate tectonic region of south-west Western Australia, which presents a significant seismic hazard to the population of Perth, have been less conclusive. Analysis of repeat GPS data has not reliably resolved deformation in this region (Featherstone, 1998).

Therefore, the small amount of deformation expected in this region will only be detected by a long time-series of GPS data collected using the GPS Receiver Pool at sites where the choke-ring antennae are permanently mounted.

All of the future field-campaigns in these regions will be executed in the most cost-effective way by the sporadic deployment of instruments from the GPS Receiver Pool. To ensure reliable detection of small surface motion requires the installation of permanent survey monuments, which must be occupied on a quasi-permanent basis with Receiver Pool GPS receivers. In some critical locations, such as in Western Australia, the additional choke-ring antennae will remain permanently on the monuments so as to eliminate possible discontinuities in the geodetic time-series, which can be caused by removing and replacing the antennae.

\section{GPS-geodesy in Antarctica}

Isostatic rebound is a geophysical phenomenon that occurs due to deglaciation after the last Ice Age, but also due to contemporary deglaciation from the effects of 'global warming'. When ice and snow are deposited on the Earth's surface, they slowly deform the crust downwards; when the ice is removed, the Earth's surface slowly rebounds. Monitoring of postglacial rebound will lead to an improved understanding of the viscoelastic structure of the Earth's crust. So far, the uplift rate in Antarctica has been estimated to range from 0 to $10 \mathrm{~mm} / \mathrm{yr}$ (Zwartz et al., 1999; Tregoning et al., 1999a). However, despite the number of surveys already conducted, there are currently insufficient GPS data to allow a reliable estimate to be made of postglacial rebound in Antarctica.

The GPS Receiver Pool will permit the consortium members to commit more of their existing GPS receivers to long-term installations in Antarctica, thereby increasing the reliability of the estimates of contemporary isostatic rebound in this region. As a continuation of an existing project, choke-ring antennae will be placed around Beaver Lake (Figure 4) for a five-year period. The GPS receivers will be powered by a combination of solar panels in the southern summer and a hydrogen-based fuel cell throughout the Antarctic winter period (cf. Figure 5).
A satellite-based communications system will be used to transfer the GPS data back to Australia in near real-time.

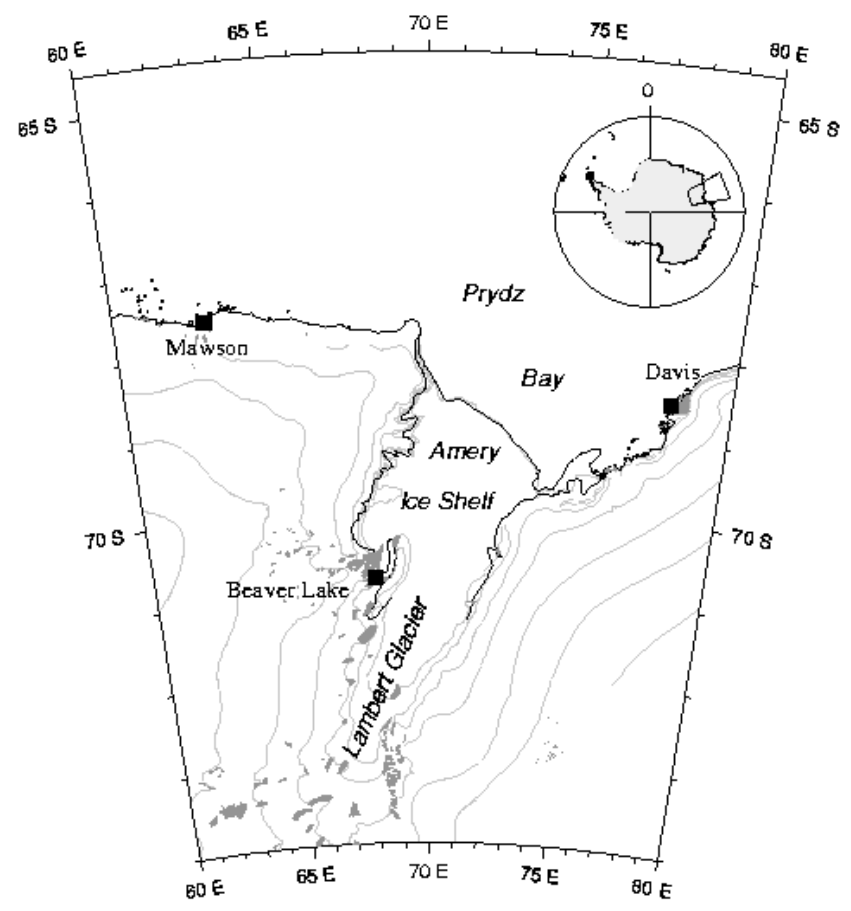

Figure 4. Locations of the GPS sites near Lambert Glacier, Antarctica

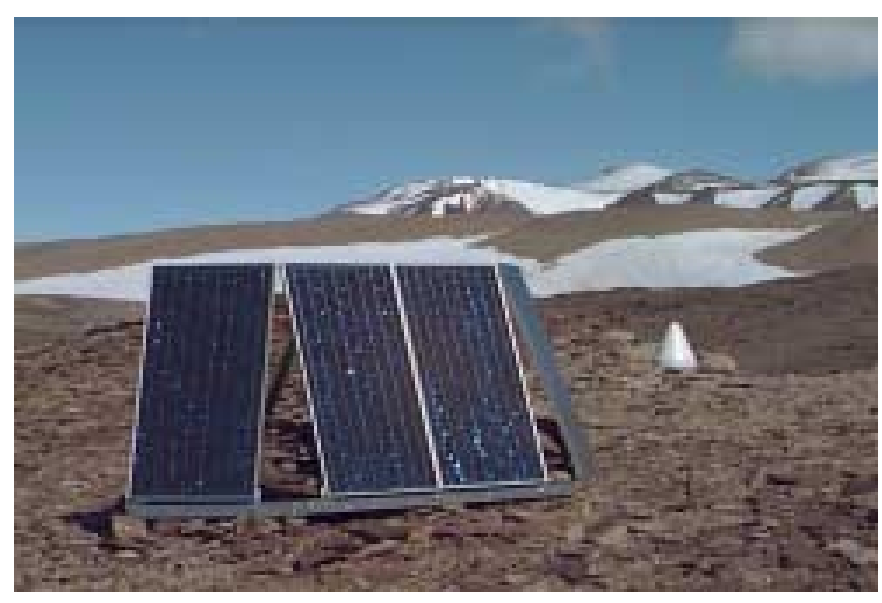

Figure 5. The 1998 solar-powered GPS system and antenna with radome at Beaver Lake, Antarctica

The GPS Receiver Pool will also contribute to estimating and monitoring the mass balance of the Antarctic ice sheet, which forms another important contribution to our understanding of climate change (cf. Hamilton et al., 1998). Previous work by the consortium members has used repeat GPS traverse data to measure height and slope changes along the Lambert Glacier Basin (Manson et al., 1998). More recent campaigns have shown that the Amery Ice Shelf is floating in regions where it was previously thought to be grounded (King et al., 2000). A much-needed requirement of this project is to make long-term GPS measurements on the grounded Antarctic ice sheet and on the moving ice shelf regions over larger spatial scales using the GPS Receiver Pool. Kinematic and static GPS data on the Amery Ice Shelf and around the Lambert Glacier Basin have also been used to calibrate the ERS-1 and ERS-2 
satellite radar altimeters in order to compute a high-accuracy elevation model of the region. These data form a basis for on-going monitoring of the Antarctic ice sheet mass balance and ice-shelf dynamics, and will provide calibration estimates for on-going satellite radar/laser missions, such as Cryosat and ICESAT.

\section{Vertical motion monitoring at tide gauges}

Global sea-level variations occur over a wide spectrum of both temporal and spatial scales. Tide-gauge studies of global sea-level change suggest that the global eustatic rate of sea-level rise during the last century ranges from $1 \mathrm{~mm} / \mathrm{yr}$ to $2.5 \mathrm{~mm} / \mathrm{yr}$, with a central value of $1.8 \mathrm{~mm} / \mathrm{yr}$. These estimates are corroborated by measurements made using satellite radar altimetry (Nerem and Mitchum, 1999). Changes in global climate and the associated sea-level rise, together with an apparent subsidence of populous coastal cities, have major impacts on the economy, environment, societal and human utilisation, especially in the Asia-Pacific region. The ability to accurately measure the long-term ( $>10$ years) sea-level change over the global oceans and its characterisation is a critical requirement for studying global climate change phenomena.

Tide-gauges located near continental margins provide estimates of long-term sea-level change. However, these estimates suffer from local land movements (eg. due to postglacial rebound, subsidence or tectonic uplift).

Therefore, any vertical deformation of the land must be monitored and removed from the tide-gauge records. Without this activity, variations in the tide-gauge records could be misinterpreted as changes in sea level. With the GPS Receiver Pool, it will be possible to make observations at a number of critical tide-gauge sites around Australia (cf. Ananga et al., 1995). Again, some of the additional chokering antenna will be deployed permanently at these sites. Together, this will allow a more reliable study of the longterm motion of coastal stations in conjunction with the tidegauge records.

As a by-product of this activity, the altimeter calibration phase of the future Jason-1 and Envisat satellite missions will use the GPS Receiver Pool. This will be achieved using the absolute calibration site at Burnie, Tasmania (White et al., 1994). This aspect of the consortium's GPS-geodetic research forms part of an international contribution involving several national and international agencies.

\section{Atmospheric sounding using GPS}

Atmospheric refraction of GPS signals as they pass through the ionosphere and troposphere impedes high-accuracy GPS positioning (eg. Lin et al., 1998). However, given an accurately known ground position and the positions of the satellites (via the IGS precise orbits for example), the amounts of atmospheric refraction can be quantified. This has opened new GPS-geodetic research areas in mapping water vapour in the troposphere (eg. Tregoning et al., 1998c; Manson et al., 1998) and the amount of ionisation of atoms and molecules in the ionosphere (eg. Lin and Rizos, 1996; Fu et al., 1999). This information will make useful contributions to, for example, weather prediction and radio communications.
An important new initiative that is possible with the GPS Receiver Pool is the establishment of GPS stations for the monitoring of precipitable water vapour content at selected points in Australia, as well as in the neighbouring countries to our north. Several of the consortium partners are currently launching new initiatives in this new area of 'GPS meteorology'. This may lead to improved atmospheric models for use in weather and drought prediction and mapping.

\section{Local deformation monitoring}

Monitoring of the deformation of natural surface features and human-made objects forms an important new application of GPS-geodetic techniques. Local deformation surveys can use a range of static, rapid-static and kinematic GPS techniques. The GPS Receiver Pool will contribute to these studies by providing the permanent receivers necessary to form core infrastructure for local monitoring networks. Most consortium members are very active in developing systems and techniques for monitoring a wide variety of structures using the GPS (eg. Ding et al., 1996; Duckrell and Stewart, 1998). The applications being investigated range from highaccuracy GPS measurements on volcanos to bridge, tall building, dam and mine-wall monitoring. The emphasis for these systems is on reliability, safety (ie., timely warning of catastrophic events) and cost-effectiveness.

Recent research by some of the consortium members on steep-slope stability monitoring has focussed on open-cut mine walls (Stewart et al., 1996). These are designed to be as steep as possible so as to reduce the volume of waste material mined. However, these designs are accompanied by frequent mechanical failures, precursors of which have been traditionally determined by terrestrial surveying techniques. This environment is particularly challenging for the GPS because multipath and limited satellite visibility reduce the reliability and accuracy of the computed positions (eg. Jia et al., 1998). Future work by the consortium members will continue to concentrate on resolving these issues and the GPS Receiver Pool will be used to collect data in open-cut mines and on other steep-slopes.

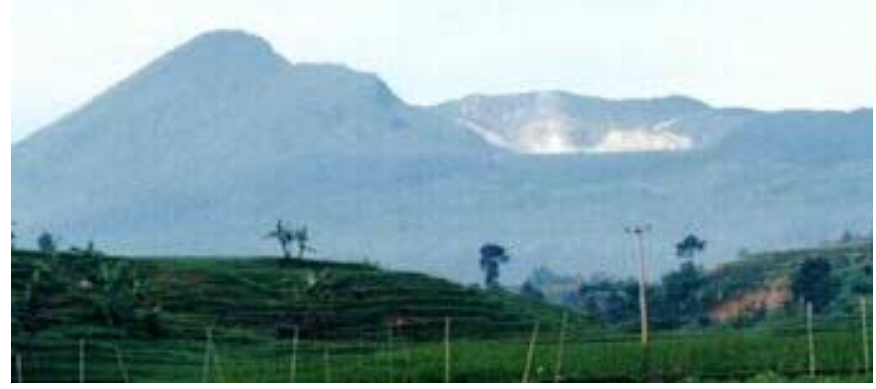

Figure 6. The Mt Papanadayan volcano, Java

GPS-geodetic techniques are well suited to the determination of deformation on the flanks of active volcanoes as a precursor to imminent eruptions. This is because a low-cost set of receivers can be left on the volcano, surrounded by receivers from the GPS Receiver Pool to model atmospheric errors, thus avoiding harm to the geodetic surveyors should the volcano erupt (Rizos et al., 1997). Recent work in this 
regard has seen the first deployment of such a system on the Mt Papanadayan volcano in 1999 (Figure 6).

Consortium members have applied and will continue to apply GPS-based monitoring to engineering structures, such as bridges, tall buildings and dams. Future research will use the GPS Receiver Pool to establish permanent test networks for this type of deformation monitoring. For example, one dam in Western Australia will be monitored using the GPS Receiver Pool.

\section{Kinematic and rapid-static GPS-geodesy}

The accurate determination of the position of a large number of stations on a regular basis to determine station velocities is a challenge, which is not efficiently addressed using traditional GPS-geodetic techniques based on campaign-style surveys. Such surveys are constrained by the limited number of GPS receivers and the long observation time periods required (typically 4-6 days).

Consortium members are investigating new techniques of long range 'rapid-static' and 'kinematic' GPS positioning (Colombo and Rizos, 1996; Feng and Han, 1996; Feng et al., 1996; Han, 1995; 1997a and b; Han and Rizos, 1996b, c and d and 1997; Wang et al., 1997; 1998a and 1998b; Wylde and Featherstone, 1995). Such techniques permit rapid, highaccuracy positioning over baselines of up to several hundreds of kilometres in length. Therefore, many more benchmarks could be observed in an epoch, and applications where long observation periods may not be possible would become more viable (Rizos and Han, 1998).

The GPS Receiver Pool will provide the infrastructure to allow experimentation of emerging rapid GPS-geodetic positioning techniques. The facility to establish large test networks will aid developments in not only long range rapidstatic and kinematic positioning, but also in the associated areas of quality control of GPS measurements, stochastic modelling and systematic error mitigation. The consortium's research in this topic will be enhanced because specific data can be collected for these experiments, which was not previously possible on a routine or as-needed basis.

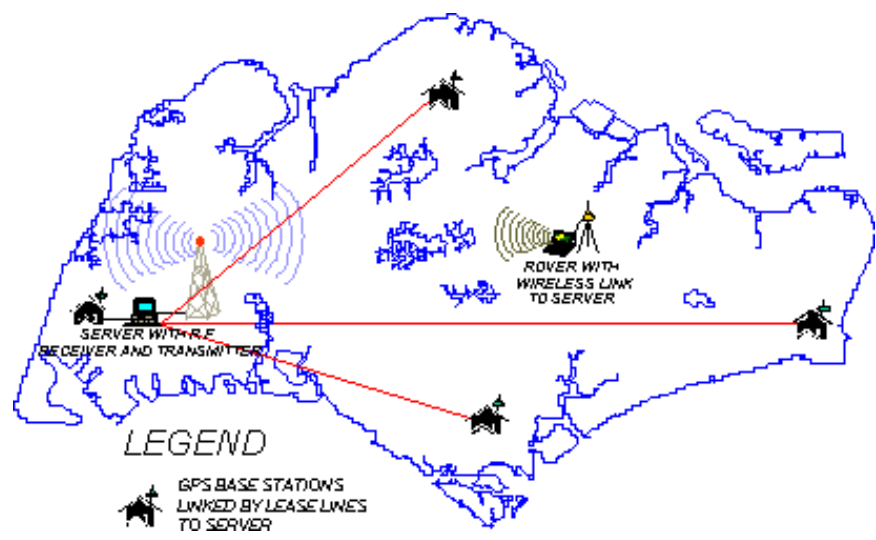

Figure 7. An example of a permanent GPS test network in Singapore

As an example of the type of GPS infrastructure implementation that would benefit static, rapid-static and kinematic GPS positioning over baseline lengths of many tens of kilometres in length, reference is made to the Singapore multi-reference GPS station network (Figure 7). This network implements multi-reference station techniques in an operational environment. The four reference receivers are connected to a single web-server by dedicated telephone lines. The data from all receivers are processed in real-time, and 'corrections' are broadcast to users (or made available for post-processing); see Rizos et al., 1997, Han and Rizos, 1997, for details of the processing methodology. Such infrastructure configurations will be tested in Australia, in controlled experiments, using the GPS Receiver Pool.

All of the above projects involve GPS experiments, algorithm and software development, sophisticated data processing, and interpretation of the positioning results. Importantly, all of these research projects have been or are being funded by the Australian Research Council, government and industry. This demonstrates the scientific and practical relevance of the research undertaken by consortium members.

\section{CONCLUDING REMARKS}

The 1999 Australian Research Council RIEFP grant and supplementary funds from five Australian universities has allowed the creation of the first ever Australian university GPS Receiver Pool that is dedicated to academic GPS research. This Pool will be used to enhance existing and new GPS-geodetic research projects among the collaborators. These projects include deformation monitoring on local and regional scales, vertical monitoring of tide-gauge sites, Antarctic geodesy and glaciology studies, kinematic and rapid-static GPS-geodesy, atmospheric sounding, and a range of complementary GPS-geodetic projects.

There are several important benefits that result from the formation of this consortium. Whereas the investigators comprising the consortium already had an excellent working relationship, the formation of this consortium and the award of the ARC grant formalise these arrangements. Also, the pooling of scarce research resources allows a wider range of existing and new research projects to be investigated.

Essentially, many of the research projects described in this paper could not continue to be investigated fully without the GPS Receiver Pool. As well as strengthening the research activities in Australia, the GPS Receiver Pool will contribute to a number of projects in South-east Asia and Antarctica, thus raising the profile of and benefits provided by Australian geodesy.

The scientific activities of the consortium using the GPS Receiver Pool are considered to be most beneficial to Australia and its neighbours. The development of new GPS data collection and processing strategies will improve the accuracy and reliability of GPS positioning in areas that are currently prohibitive to this technology. This, in turn, will increase the number of applications of GPS in surveying and navigation. All of the scientific research activities in this paper also confer both tangible and intangible benefits. For instance, studies of plate tectonics, volcanoes and global warming contribute to the quality of our life and may one day help predict the onset of natural disasters.

To conclude, the formation of the consortium and the diversity of the GPS-geodetic research projects to be 
investigated using the GPS Receiver Pool will undoubtedly benefit Australian geodesy.

\section{ACKNOWLEDGEMENTS}

We would like to thank the Australian Research Council, the University of New South Wales, Curtin University of Technology, The University of Tasmania, and the University of Canberra for providing the funding for the GPS Receiver Pool. We would also like to thank the reviewers for their constructive comments on an earlier version of this manuscript.

\section{REFERENCES}

Ananga N., R. Coleman and C. Rizos (1995) Geodetic monitoring of tide-gauge bench marks with GPS. Journal of the Geodetic Society of Japan, 41(1), 91-97.

Coleman, R. [ed] (1999) Geodesy in Australia: National Report 1995-99, Report to the International Union of Geodesy and Geophysics XXII General Assembly, Birmingham, England, http://www.science.org.au/internat/natcomm/geodesy.pdf.

Colombo, O.L. and C. Rizos (1996) Testing high-accuracy longrange carrier-phase DGPS in Australasia. In: GPS Trends in Precise Terrestrial, Airborne, and Spaceborne Applications, Springer, Berlin, 226-230.

Ding X., R. Coleman and M.J. Rotter (1996) Technique for precise measurement of large-scale silos and tanks. Journal of Surveying Engineering, 122(1), 14-25.

Drane C.R. and C. Rizos (1997) Positioning systems in intelligent transportation systems. Artech House, Boston, ISBN 0-89006-536-5, 369pp.

Duckrell, R. and M.P. Stewart (1998) GPS monitoring of North Dandalup Dam, Western Australia, Proceedings of International Workshop on Advances in GPS Deformation Monitoring, Perth, WA, September, Paper No. 10.

Featherstone W.E. (1995) The Global Positioning System (GPS) and its use in geophysical exploration. Exploration Geophysics, 26(1), 1-18.

Featherstone, W.E. (1998) Geodetic monitoring of the South West Seismic Zone, Proceedings of International Workshop on Advances in GPS Deformation Monitoring, Perth, WA, September, Paper No. 5.

Feng, Y. and S. Han (1996) A long-range dynamic GPS system and positioning results. Proceedings of the IEEE Position Location and Navigation Symposium, Atlanta, Georgia, April, 711-718.

Feng, Y., K. Kubik and S. Han (1996) A long-range dynamic GPS positioning system and its test results. International Archives of Photogrammetry and Remote Sensing, XXXI(B1), 65-71.

Fu W.X., S. Han, C. Rizos, M. Knight and A. Finn (1999) Realtime ionospheric scintillation monitoring using GPS. Proc. of 12th Int. Tech. Meeting of the Satellite Division of the U.S. Inst. of Navigation, Nashville, Tennessee, September.

Hamilton, G.S., I.M. Whillans and P.J. Morgan (1998) First point measurements of ice-sheet thickness change in Antarctica, Annals of Glaciology, 27, 125-129.

Han S. (1995) Ambiguity recovery for GPS long range kinematic positioning. Proc. of 8th Int. Tech. Meeting of the Satellite Division of the U.S. Inst. of Navigation, Palm Springs, California, September, 349-360.

Han S. (1997a) Quality control issues relating to ambiguity resolution for real-time GPS kinematic positioning. Journal of Geodesy, 71(6), 351-361.

Han S. (1997b) Ambiguity recovery for GPS long range kinematic positioning. Navigation, 44(2), 257-266.

Han S. and C. Rizos (1996a) GPS network design and error mitigation for real-time continuous array monitoring systems. 9th International Technical Meeting of the Satellite Division of the U.S. Institute of Navigation, Kansas City, Missouri, September, 1827-1836.

Han S. and C. Rizos (1996b) Centimeter GPS kinematic or rapid static survey without ambiguity resolution. Surveying and Land Information Systems, 56(3), 143-148.

Han S. and C. Rizos (1996c) Progress and constraints of realtime carrier phase-based marine GPS positioning. In: Gravity, Geoid and Marine Geodesy, J. Segawa, H. Fujimoto \& S. Okubo (eds.), Springer, Berlin, 712-719.

Han S. and C. Rizos (1996d) On-the-fly ambiguity resolution for long-range GPS kinematic positioning. In: GPS Trends in Precise Terrestrial, Airborne and Spaceborne Applications, Springer, Berlin, 290-294.

Han S. and C. Rizos (1997) An instantaneous ambiguity resolution technique for medium-range GPS kinematic positioning. 10th International Technical Meeting of the Satellite Division of the U.S. Institution of Navigation, Kansas City, Missouri, September, 1789-1800.

Han S., C. Rizos and R. Abbot (1999) Sea surface determination using long-range kinematic GPS positioning and Laser Airborne Depth Sounder techniques. Marine Geodesy, 22(3): 195-203.

Jia M., M. Tsakiri and M.P. Stewart (1998) A reweighted filtering algorithm and its application in open pit deformation monitoring. In: Advances in Positioning and Reference Frames,, F.K. Brunner (ed.), Springer, Berlin, 369-374.

King, M.A, N.L. Nyugen, R. Coleman and P.J. Morgan (2000) GPS Measurements on the Amery Ice Shelf, East Antarctica, GPS Solutions, 3(4) (in press)

Lin L.S. and C. Rizos (1996) An algorithm to estimate GPS satellite and receiver L1/L2 differential delay biases and its application to regional ionosphere modelling. Geomatics Research Australasia, 65, 1-26.

Lin L.S., C. Rizos and S.P. Mertikas (1998) Real-time failure detection and repair in ionospheric delay estimation using GPS by robust and conventional Kalman filter state estimates. In: Advances in Positioning and Reference Frames, F.K. Brunner (ed.), Springer, Berlin, 295-300.

Manning, J., R. Govind and P. Holland (1998) The monitoring of national and regional geodetic networks, Proceedings of International Workshop on Advances in GPS Deformation Monitoring, Perth, WA, September, Paper No. 1.

Manson, R., M. King and R. Coleman (1998) GPS: putting it on ice, Proceedings of the Thirty-ninth Australian Surveyors Congress, Launceston, Tasmania, November, 31-42.

Morgan P.J., Y. Bock, R. Coleman, P. Feng, D. Garrard, G. Johnston, G. Luton, B. McDowall, M. Pearse, C. Rizos and R. Tiesler (1996) A zero order GPS network for the Australian region. UNISURV S-46, School of Geomatic Engineering, The University of New South Wales.

Nerem, S. R. and G. T. Mitchum (1999) Sea level changes, In: Satellite Altimetry and Earth Sciences, L.-L. Fu and A. Cazenave (eds.), Academic Press (in press).

Phillips H.A., I. Allison, R. Coleman, G. Hyland, P.J. Morgan, N.W. Young (1998) Comparison of ERS satellite radar altimeter heights with GPS-derived heights on the Amery Ice Shelf, East Antarctica. Annals Glaciology, 27: 19-24.

Rizos C. and S. Han (1998) High-precision GPS kinematic positioning: progress and outlook. In: Advances in Positioning and Reference Frames, F.K. Brunner (ed.), Springer, Berlin, 319-324.

Rizos C., S. Han and C. Roberts (1997) Permanent automatic low-cost GPS deformation monitoring systems: error mitigation strategies and system architecture. 10th International Technical Meeting of the Satellite Division of the 
U.S. Institute of Navigation, Kansas City, Missouri,

September, 909-917.

Roberts C. and C. Rizos (1998) Permanent automatic GPS

deformation monitoring systems: a review of system architecture and data processing strategies. In: Advances in Positioning and Reference Frames, F.K. Brunner (ed.), Springer, Berlin, 375-380.

Stewart M.P. and G.H. Ffoulkes-Jones (1995) A GPS software package for ground deformation monitoring. Cahier du Centre European de Geodynamique et de Seismologie, ECGS, Luxembourg, 8, 149-158.

Stewart M.P., M. Tsakiri and X. Ding (1996) GPS navigation techniques in open pit deformation monitoring. 9th International Technical Meeting of Satellite Division of the Institute of Navigation, Kansas City, Missouri, September, 1225-1231.

Stewart, M.P., X. Ding, M. Tsakiri and W.E. Featherstone (1997) The 1996 STATEFIX Project, Final Contract Report to the Department of Land Administration, Perth, Australia, approx. 100pp.

Tregoning P., K. Lambeck, A. Stolz, P.J. Morgan, S.C. McClusky, P. van der Beek, H. McQueen, R.J. Jackson, R.P. Little, A. Laing and B. Murphy (1998a) Estimation of current plate motions in Papua New Guinea from Global Positioning System observations Journal of Geophysical Research, 103(B6), 12,181-12,203.

Tregoning P., F. Tan, J.R. Gilliland, H. McQueen and K. Lambeck (1998b). Present-day crustal motion in the Solomon Islands from GPS observations. Geophysical Research Letters, 25, 3627-3630.

Tregoning, P., R. Boers, D. O'Brien and M. Hendy (1998c) Accuracy of precipitable water vapour estimates from GPS observations, Journal of Geophysical Research, 103: 2870128710.

Tregoning, P., R. Twilley, M. Hendy and D. Zwartz (1999a) Monitoring isostatic rebound in Antarctica using continuous remote GPS observations, GPS Solutions, 2, 70-75.

Tregoning, P, R.J. Jackson, H. McQueen, K. Lambeck, C. Stevens, R.P. Little, R. Curley and R.Rosa (1999b) Motion of the south Bismarck plate, Papua New Guinea, Geophysical Research Letters, 26: 3517-3520.

Wang J.L., M.P. Stewart and M. Tsakiri (1997) A new validation test procedure for ambiguity resolution on-the-fly. International Symposium on Kinematic Systems in Geodesy, Geomatics and Navigation, Banff, Canada, June, 279-287.

Wang, J.L., M.P. Stewart and M. Tsakiri (1998a) A discrimination test procedure for ambiguity resolution on-thefly, Journal of Geodesy, 72(11), 644-653.

Wang, J.L., M.P. Stewart and M. Tsakiri (1998b) Kinematic GPS positioning with adaptive Kalman filtering techniques, In: Advances in Positioning and Reference Frames, F.K. Brunner (ed), Springer, Berlin, 389-394.

Watson, C. and R. Coleman (1998) The Batman Bridge: Structural monitoring using GPS, Proceedings of International Workshop on Advances in GPS Deformation Monitoring, Perth, WA, September, Paper No. 7.

White N.J., R. Coleman, J.A. Church, P.J. Morgan and S.K. Walker (1994) A southern hemisphere verification for the TOPEX/POSEIDON satellite altimeter mission. Journal of Geophysical Research, 99(C12), 24505-24516.

Wylde, G.P. and W.E. Featherstone (1995) An evaluation of some stop-and-go kinematic GPS survey options. The Australian Surveyor,40(3), 205-212.

Zwartz, D., P. Tregoning, K. Lambeck, P. Johnston and J. Stone (1999) Estimates of present-day glacial rebound in the Lambert Glacier region, Antarctica, Geophysical Research Letters, 26: 1461-1464. 